\title{
Peptic Esophageal Stricture in children: A Case report \& review of literature
}

\section{Patel NP, Gedam DS}

Dr Narmada Prasad Patel, Assistant Professor in Medicine, Dr D Sharad Gedam, Professor of Pediatrics. Both are affiliated with L N Medical College, Bhopal, India

Address for correspondence: Dr Narmada Prasad Patel, Email: narmadapatel2006@rediffmail.com

\begin{abstract}
Peptic esophageal stricture is a common complication of gastroesophageal reflux disease (GERD). Though thought to be common in childhood but often go undetected in developing country like India due to lack of awareness and limited resources. We are presenting this case because radiologically it was looking like a case of Achalasia cardia but after endoscopy it turned out to be a case of esophageal strictures.
\end{abstract}

Key words: Esophageal stricture, Achalasia cardia, GERD, Dysphagia

\section{Introduction}

Esophageal stricture is a serious complication of gastroesophageal reflux disease in childhood. This problem although common but often go unnoticed in our country due to lack of proper healthcare and diagnostic facilities ${ }^{1}$. The pathogenesis behind esophageal stricture is the injuries caused by reflux disease leading to overproduction of fibrotic tissue and formation of esophageal stricture usually in lower third ${ }^{2}$. The usual presenting clinical features are dysphagia ${ }^{3}$. We report one such case who presented to our outpatient department in order to create awareness regarding the peptic esophageal stricture as a cause of dysphasia in children.

\section{Case summary}

A three and half year old boy was brought to the outpatient department with history of vomiting after taking feeds and difficulty in swallowing since past two years. According to the mother he was apparently alright till the age of 10 to 11 months. Patient was accepting breast feeds till age of 6 month. Top milk was started after 6 month age. Patient developed complain of vomiting when semisolid was started at age of 10 to 11 month. Since then patient is not able to tolerate even a glass of milk in single sitting. Patient vomits out everything which is given in large amount. This complain is progressively increasing and the patient is not gaining weight. On examination patients looked thin built, underweight for his age with weight below $3^{\text {rd }}$ centile for his age with poor nutritional status with loss of subcutaneous fat. He was afebrile, pallor + , no icterus . On systemic examination no organomegaly were observed in per abdomen. Respiratory system examination revealed adequate air entry bilaterally with no added sounds. Cardiovascular and neurological system examination was normal. He was admitted in pediatric ward. Base line investigations were sought which revealed $\mathrm{Hb}=10.7 \%$, TLC $=9600$, Platelet count $=3.5$ lakh, urine examination was normal, kidney and liver function were in normal range, bleeding and clotting time were normal, ultrasonography of abdomen was within normal limits.

Barium swallow revealed a dilated esophagus and hiatus hernia. Patient was further investigated with upper gastrointestinal endoscopy under general anaethesia which also confirmed a grossly dilated esophagus and added that a stricture was present at $20 \mathrm{~cm}$ level beyond which the endoscope could not be negotiated. A diagnosis of peptic esophageal stricture secondary to gastro esophageal reflux disease was made. The child was subjected to endoscopic stricture dilatation and discharged after being better. Child complaints improved and his condition was much better on subsequent visit after 15 days.

\section{Discussion}




\section{Case Report}

The most common and challenging gastrointestinal motility disorders in children include gastro esophageal reflux disease (GERD), esophageal achalasia, gastro paresis, chronic intestinal pseudo-obstruction, and constipation ${ }^{4}$. Gastro esophageal reflux, the passage of gastric contents into the esophagus, is a normal physiologic process; pathologic gastro esophageal reflux, or GERD, is a condition in which gastro esophageal reflux causes symptoms (frequent heartburn, regurgitation, and/or vomiting) and complications (esophagitis, strictures, and/or extra intestinal manifestations). GERD may be caused by mechanical factors, such as the increased frequency of transient lower esophageal sphincter (LES) relaxations or

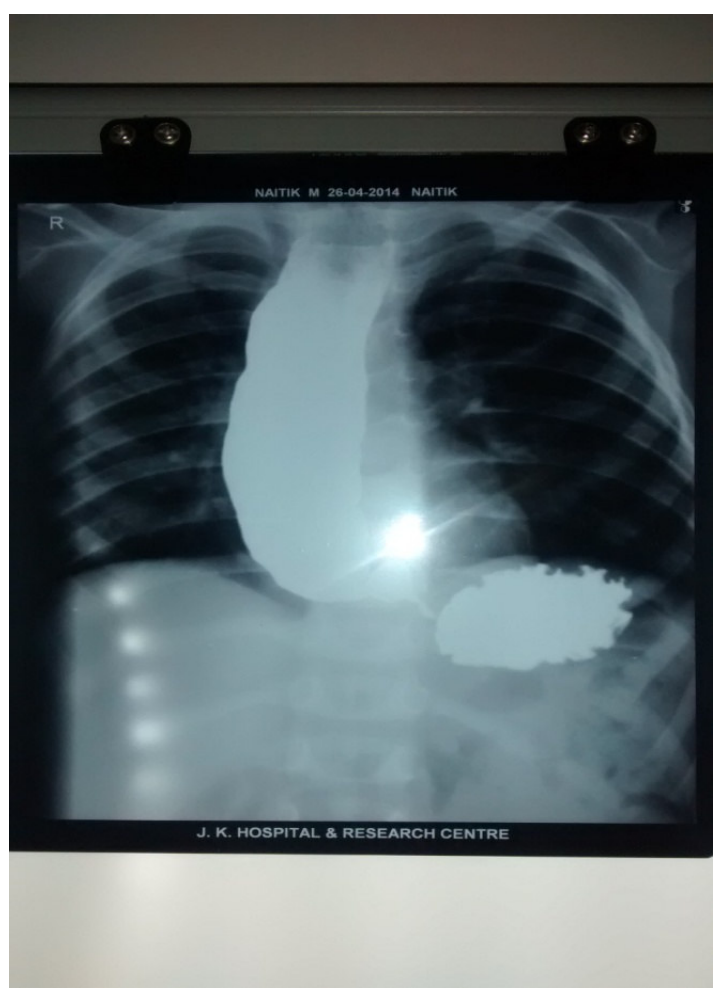

Fig 1: Barium swallow showing dilated esophagus

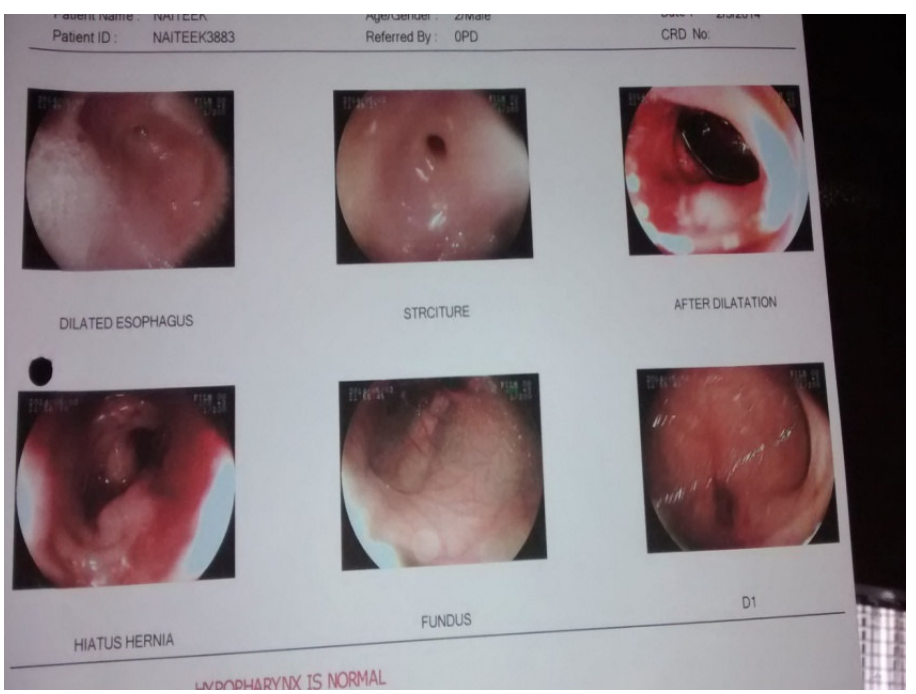

Fig 2: Endoscopy Showing stricture\& Hiatus hernia

the presence of hiatus hernia or delayed gastric emptying, or by other factors, such as increased gastric acid secretion or

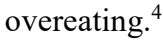

Peptic strictures are results of chronic irritation caused by reflux esophagitis. They contribute to around $90 \%$ of benign esophageal strictures. Stricture formation occur in $7-23 \%$ of patients with reflux esophagitis. ${ }^{5}$ The most common presentation of esophageal stricture is insidious onset of dysphasia specially to the solid foods. In children these symptoms may be confused with many psychological factors and may be often detected late usually in developing and underdeveloped countries.

Endoscopic dilatation of esophageal stricture is usually a safe and effective intervention especially in children.

Conclusion: Peptic esophageal stricture is a common sequel of gastro esophageal reflux disease in children. This case is reported to create awareness among medical fraternity about the common complication of GERD. Early diagnosis can improve the prognosis of serious disorder.

\section{Reference}

1. Shehata SM, Enaba ME. Endoscopic dilatation for benign oesophageal strictures in infants and toddlers: Experience of an expectant protocol from North African tertiary centre. Afr J Paediatr

Surg 2012;9:187-92.

2. Repici A, Conio M, De Angelis C, Battaglia E, Musso A, Pellicano R,et al. Temporary placement of an expandable polyester siliconecovered stent for treatment of refractory benign esophageal strictures.Gastrointest Endosc 2004;60:513-9. 
3. Khanna N. How do I dilate a benign esophageal stricture? Can JGastroenterol 2006;20:153-5.

4. Ambartsumyan L, Rodriguez L. Gastrointestinal Motility Disorders in Children. Gastroenterology \& Hepatology 2014;10(1):16- 26.

5. Achem SR, Devault KR. Dysphagia in aging. J Clin Gastroenterol 2005;39:357-71.

\section{How to cite this article?}

Patel NP, Gedam DS. Peptic Esophageal Stricture in children: A Case report \& review of literature. Pediatr Rev: Int J Pediatr Res 2014;1(1):28- 30. doi: 10.17511/ijpr.2014.i01.06 